Revista IBERC

v. 4, n. 3, p. 147-151, set./dez. 2021

www.responsabilidadecivil.org/revista-iberc

DOI: https://doi.org/10.37963/iberc.v3i2.189

\title{
A BASE SÓLIDA DO DIREITO MÉDICO CONSTRUÍDA APÓS TRÊS DÉCADAS DE LIÇÕES DO PROF. MIGUEL KFOURI NETO: UMA RESENHA À 11 ${ }^{\mathrm{a}}$ EDIÇÃO DA OBRA "RESPONSABILIDADE CIVIL DO MÉDICO"
}

THE SOLID BASES OF MEDICAL LAW BUILT AFTER THREE DECADES OF PROF. MIGUEL KFOURI NETO'S LESSONS: A REVIEW OF THE $11^{\text {TH }}$ EDITION OF THE BOOK "RESPONSABILIDADE CIVIL DO MÉDICO"

Rafaella Nogaroli

"Os advogados dos autores pintam com tintas carregadas as evidências de má prática médica, ao passo que os patronos dos requeridos, respaldados em compêndios científicos e laudos periciais, demonstram que o profissional em momento nenhum afastou-se dos cânones que a ciência médica estabelece para o procedimento questionado." [Kfouri Neto, 2021]

Em setembro de 2021, o livro "Responsabilidade Civil do Médico" completa quase três décadas - mais precisamente, 27 anos -, desde seu lançamento pela editora Revista dos Tribunais, em 1994. Fruto da dissertação de Mestrado em Direito desenvolvida sob orientação do professor João Batista Lopes, na Universidade Estadual de Londrina (UEL), Miguel Kfouri Neto oferece uma obra com importantes matizes, apta a subsidiar, com proficiência, os inúmeros debates relacionados ao referido tema. Com aceitação plena, por parte da comunidade jurídica e médica - haja vista a celeridade com que os exemplares se esgotaram, ao longo dos anos - esta nova edição, a décima primeira, assim como as demais que a precederam, foi revista e ampliada.

O professor Kfouri pesquisa e escreve sobre direito médico há cerca de 32 anos, desde a elaboração de monografia versando sobre a responsabilidade civil do médico, na segunda metade de 1989, como requisito parcial à obtenção dos créditos referentes à disciplina Direito Civil I, prelecionada por Batista Lopes, no curso de mestrado da UEL. Na época, o tema, em países como França, Itália, Espanha e Argentina, já era abordado em obras e tratados volumosos, escritos por civilistas de renome. No Brasil, contudo, predominavam os trabalhos elaborados por médicos, professores de medicina legal - enquanto os mestres do Direito Civil apenas incidentalmente se ocupavam da questão -, enfocando-

\footnotetext{
' Assessora de Desembargador no Tribunal de Justiça do Estado do Paraná (TJPR). Mestranda em Direito das Relações Sociais pela Universidade Federal do Paraná (UFPR). Especialista em Direito Médico e Bacharel em Direito pelo Centro Universitário Curitiba (UNICURITIBA). Especialista em Direito Aplicado pela Escola da Magistratura do Paraná (EMAP) e em Direito Processual Civil pelo Instituto de Direito Romeu Felipe Bacellar. Coordenadora do grupo de pesquisas em "Direito da Saúde e Empresas Médicas" (UNICURITIBA), ao lado do prof. Miguel Kfouri Neto. Diretora adjunta e membro titular do Instituto Brasileiro de Estudos de Responsabilidade Civil (IBERC). Integrante do grupo de pesquisas em direito civil-constitucional "Virada de Copérnico" (UFPR). Email: nogaroli@gmail.com / ORCID: https://orcid.org/0000-0002-5046-1396
} 
a em conjunto com as demais modalidades de responsabilidade civil ou em breves artigos. Por isso, Kfouri foi precursor doutrinário, ao defender dissertação sobre a temática em 1993.

Desde a $1^{\text {a }}$ edição do livro, Miguel Kfouri Neto traz importantes lições sobre os conceitos básicos que permeiam a responsabilidade civil médica. Ele indica que a responsabilidade é subjetiva, calcada na culpa stricto sensu (imperícia, negligência ou imprudência) e o encargo assumido pelo médico configura obrigação de meios, e só por exceção constituirá obrigação de resultado. Diante disso, o autor explica os desdobramentos, quanto ao ônus da prova: "ao paciente/vítima incumbirá apenas demonstrar que o resultado não foi alcançado, e ao médico competirá a prova de um fato que o exima da responsabilidade". Já nos casos excepcionais de obrigação de resultado, "a vítima deverá fazer prova de que o médico não agiu com o grau de diligência razoável e houve descumprimento culposo".

A culpa do profissional médico constitui um dos problemas científicos e deontológicos, antes que jurídicos, mais antigos, objeto de debates potencialmente infinitos, dada a natureza particular da atividade médica. Nem sempre, nos domínios da responsabilidade médica, o reconhecimento do nexo de causalidade é tarefa fácil, visto que "os médicos dizem que não há doenças, há doentes, porquanto dois pacientes, acometidos do mesmo mal e tratados de modo idêntico, podem apresentar reações absolutamente distintas à terapia: num caso, a cura; noutro, o agravamento da enfermidade e, até a morte". A Medicina não é ciência exata e a álea terapêutica está sempre presente. Por isso, Kfouri afirma que, nas demandas sobre responsabilidade civil médica, espera-se do julgador um olhar atento à reconstrução dos fatos a partir dos elementos de que dispõe, especialmente da prova pericial.

Incumbirá ao magistrado avaliar a perícia, sopesando explicações e conclusões dos peritos, a fim de decidir se deve acatar o laudo, não somente porque este provém de técnicos, mas "sobretudo pela força persuasiva das razões submetidas ao crivo analítico, autônomo e soberano do julgador". Kfouri defende a ideia de que o juiz deve utilizar todos os indícios suficientemente razoáveis nos autos do processo para tornar sua convicção legítima, pois existe uma lógica no desenvolvimento dos fatos, mesmo os biológicos. Deverá ser estabelecido se o dano é mesmo consequência da ação culposa do profissional, ou é atribuível a causa diversa ou desconhecida. Kfouri assevera a importância de o julgador inteirar-se da questão crucial a ser elucidada, tão logo seja contestada a lide, elaborando os quesitos que submeterá ao perito, juntamente com aqueles oferecidos pelas partes. Ao redigir os quesitos, o magistrado já precisa ter uma ideia clara das questões fundamentais da demanda, fator decisivo, também, para a produção de uma boa prova oral.

Outra questão relevante apresentada por Kfouri cinge-se à determinação da responsabilidade civil médica decorrente de erro de diagnóstico. O diagnóstico médico nem sempre será uma tarefa fácil ao profissional e ele se reveste de certas particularidades. Quando o médico procede a um bom exame de seu paciente, com todos os dados e meios que a ciência coloca à sua disposição, e ainda assim comete um erro de diagnóstico, o profissional não será responsabilizado. Não se pode impor ao médico uma obrigação de infalibilidade ou absoluta exatidão. Contudo, quando o erro de diagnóstico for grosseiro, revelar ignorância ou negligência inadmissíveis, torna-se culposo - e aí sim conduz ao dever de indenizar. 
Nesse sentido, observa-se que não é propriamente o erro de diagnóstico que incumbe ao juiz examinar, mas sim se o médico teve culpa no modo pelo qual procedeu ao diagnóstico, se recorreu, ou não, a todos os meios a seu alcance para a investigação do quadro clínico do paciente. $O$ profissional da medicina, portanto, que não revela o cuidado exigível - com erro grosseiro na sua conduta diagnóstica - incorrerá em responsabilidade civil.

Ademais, a partir da $10^{a}$ edição, publicada em 2019, Kfouri incluiu um capítulo específico sobre o consentimento livre e esclarecido do paciente, em razão da relevância do tema. Nos tempos atuais, em que a autonomia da vontade - corolário do respeito à dignidade da pessoa - há de ser observada pelos profissionais da saúde, o descumprimento desse dever gera responsabilidade civil. Características peculiares da controvérsia, como o fato de o dano consistir na ausência de obtenção do consentimento - e não, propriamente, na lesão ou morte da vítima -, convidam-nos à reflexão. Kfouri adverte que é fundamental o juiz avaliar a distinção entre as duas hipóteses - falta de informação e nexo etiológico com o dano sofrido pelo paciente -, a fim de que resulte bem definida qual a fonte originária da reparação.

Logo, na eventualidade de o dano não ter sido causado por culpa - a intervenção médica é correta -, mas não se informa adequadamente -, surge a discussão sobre a responsabilização pela falta ou deficiência no cumprimento do dever de informar. Quanto ao nexo causal, a vítima deve demonstrar que o dano provém de um risco acerca do qual deveria ter sido avisada, a fim de deliberar sobre a aceitação ou não do tratamento.

No que toca à quantificação da indenização pela violação do dever de informação, Kfouri busca responder à seguinte indagação: "o profissional deve ser condenado ao ressarcimento integral, como se tivesse ocasionado diretamente os danos materiais e morais - ou a uma reparação parcial, relacionada não ao ato médico em si, mas à ausência do consentimento esclarecido?". A tese defendida é a de que, como o dano não é causado por má prática médica, apesar da ausência do consentimento, a indenização deve ser menor que aquela estabelecida para a hipótese de dano diretamente ocasionado por imperícia, imprudência ou negligência do profissional. Assim, o autor adverte que, ao fixar a indenização, o juiz deverá examinar alguns fatores: "a) existência de outras terapias menos perigosas ou desprovidas de potencialidade lesiva; b) se, à luz do que comumente ocorre, outro paciente, em idênticas condições, teria consentido, após se inteirar dos perigos inerentes à intervenção; c) se tais riscos, não informados, eram comuns ou excepcionais. Após, incumbirá ao julgador mensurar as consequências concretas da falta de consentimento, arbitrando reparação consentânea".

Observa-se que o livro de Kfouri tem o propósito de oferecer respostas às indagações mais frequentes, dirimindo controvérsias e apontando soluções, sobre variados debates jurídicos no contexto da atividade médica, tais como: infecção hospitalar, omissão de socorro, atuação do cirurgião plástico e do anestesiologista, os serviços médicos e o Código do Consumidor.

A responsabilidade civil médica na cirurgia plástica ganha especiais nuances. A relação médico-paciente encerra obrigação de meios, e não de resultado, salvo na hipótese de cirurgias estritamente estéticas. Neste caso, explica Kfouri que o médico se obriga a um resultado determinado e se submete à presunção de culpa correspondente e ao ônus da prova para eximir-se da responsabilidade pelo dano eventualmente decorrente da intervenção. $O$ autor ressalva que, na 
obrigação de resultado, presume-se a culpa do médico, pela simples frustração da finalidade a que se vinculava o profissional. Contudo, essa presunção não acarreta a transformação da natureza da responsabilidade do médico, que continua a ser subjetiva. Ressalta-se a hipótese das cirurgias de natureza mista - estética e reparadora -, na qual a responsabilidade do médico não pode ser generalizada, devendo ser analisada de forma fracionada. A parte estética da intervenção deve ser analisada mediante aplicação do regramento atinente às obrigações de resultado, fazendo incidir à cirurgia com finalidade reparadora a disciplina da obrigação de meios.

Quanto à culpa médica, no tópico do livro dedicado à análise da culpa civil e culpa penal, a partir da $9^{a}$ edição, foram acrescentadas considerações acerca do dolo eventual na prática médica. Há, ainda, ligeiras observações de índole processual. O capítulo da obra sobre anotações processuais às demandas indenizatórias do dano médico foi inteiramente reescrito na referida edição, à luz do Código de Processo Civil de 2015, principalmente no que toca à tutela provisória de urgência antecipada, a estabilização da tutela antecipada requerida em caráter antecedente e a produção antecipada de provas.

Além disso, desde a $8^{\mathrm{a}}$ edição da obra de Kfouri, foram incluídas noções doutrinárias e jurisprudenciais acerca da teoria da perda de uma chance na área médica. Apesar do tema ser analisado com maior profundidade em seu outro livro, intitulado "Responsabilidade Civil dos Hospitais", o autor apresenta aqui breves - e importantes - considerações gerais da teoria. Em síntese, admitese algumas situações nas quais a culpa do médico compromete as chances de vida e a integridade do paciente. O erro de diagnóstico, por exemplo, do qual advém tratamento inadequado, pode constituir perda de uma chance de cura ou sobrevivência - e abre ao paciente ou familiares a possibilidade de reparação, nos limites da perda da chance considerada.

Segundo lições de Kfouri, o elemento determinante para a indenização é a chance perdida de um resultado favorável no tratamento. Em síntese, o reconhecimento da "chance perdida" há que se apoiar em dados fáticos e científicos claramente provados, indicativos de que, caso a enfermidade tivesse sido diagnosticada com antecedência, o percentual de possibilidade de cura, indicado pela ciência médica, aumentaria. O contrário, todavia, conduziu à perda dessa chance. Vale destacar que a reparação, de acordo com o autor, não é integral, posto que não se indeniza o prejuízo final, mas sim a chance perdida. Há quem critique a aplicação dessa teoria na área médica. Inclusive, nesta $11^{\mathrm{a}}$ edição da obra, Kfouri incluiu a recente divergência doutrinária. Tem surgido uma corrente minoritária que entende ser incabível mensurar chances de recuperação, cura ou sobrevivência, pois "cálculos estatísticos não podem servir como parâmetro para uniformizar e tabelar o homem".

Nesta nova edição da obra, com o intuito de sempre proporcionar conteúdo atualizado e de qualidade, Kfouri introduziu também acréscimos indispensáveis à perfeita compreensão da culpa médica no contexto da pandemia da Covid-19. Tendo em vista que não há no ordenamento jurídico brasileiro a possibilidade de realizar a modulação da responsabilidade civil médica para os casos de atuação específica no combate à pandemia, o autor busca traçar possíveis respostas à luz das previsões do Código Civil. São delineadas considerações sobre a culpa médica na prática da prescrição off-label de medicamentos, indicando-se a necessária distinção com o tratamento meramente experimental. Kfouri afirma que a prática de prescrição off-label não é ilícita em si mesma, contudo, 
para ser adotada de modo a não constituir um elemento constitutivo de responsabilização civil, há de cumprir requisitos que justifiquem sua adoção, especialmente em face do enfrentamento de uma pandemia. Nesse sentido, ao fazer menção à tese da teoria da alteração das circunstâncias no contexto sanitário, o autor defende que os diversos padrões de licitude são flexíveis e definíveis em concreto, isto é, são necessariamente circunstanciais.

Por fim, destacam-se as importantes inserções, realizadas também nesta última edição do livro, a respeito da Resolução do CFM $n^{\circ}$ 2.232/2019, que estabelece normas éticas para a recusa terapêutica por pacientes e objeção de consciência na relação médico-paciente. Ainda, Kfouri esclarece que o STF reconheceu a existência de repercussão geral da questão constitucional suscitada no Leading Case RE 1.212.272 (Tema 1069), em que se discute o direito de autodeterminação das Testemunhas de Jeová de submeterem-se a tratamento médico realizado sem transfusão de sangue, em razão da sua consciência religiosa. $O$ autor discute um recente caso em que o Tribunal de Justiça do Rio Grande do Norte negou pedido liminar para obrigar paciente Testemunha de Jeová com Covid19, internado em estado grave, a receber transfusão. Ainda, Kfouri indica que, vem-se firmando o princípio da autonomia da vontade do paciente e, neste cenário, têm surgido demandas indenizatórias em que se pleiteia indenização em virtude de transfusão realizada sem consentimento.

Diante destas brevíssimas considerações, observa-se que Miguel Kfouri Neto atinge, com justificado júbilo, a décima primeira edição da obra "Responsabilidade Civil do Médico". Resta a nós, eternos estudantes e discípulos, a gratidão pela base sólida do direito médico construída nestas onze edições do livro, desenvolvidas ao longo de quase três décadas. Já dizia Isaac Newton que "se conseguimos ver mais longe hoje, foi por estarmos de pé sobre ombros de gigantes". O professor Kfouri é certamente o nosso gigante, um autêntico mestre, que têm proporcionado um terreno fértil de importantes debates sobre a responsabilidade civil médica.

Como citar: NOGAROLI, Rafaella. A base sólida do direito médico construída após três décadas de lições do Prof. Miguel Kfouri Neto: uma resenha à $11^{\text {a }}$ edição da obra "Responsabilidade civil do médico". Revista IBERC, Belo Horizonte, v. 4, n. 3, p. 147-151, set./dez. 2021. 